\title{
Neck soft tissue and fat distribution: comparison between normal men and women by magnetic resonance imaging
}

Adam T Whittle, Ian Marshall, Ian L Mortimore, Peter K Wraith, Robin J Sellar, Neil J Douglas

\begin{abstract}
Background-Obesity and increased neck circumference are risk factors for the obstructive sleep apnoea/hypopnoea syndrome (SAHS). SAHS is more common in men than in women, despite the fact that women have higher rates of obesity and greater overall body fat. One factor in this apparently paradoxical sex distribution may be the differing patterns of fat deposition adjacent to the upper airway in men and women. A study was therefore undertaken to compare neck fat deposition in normal men and women.

Methods-Using T1 weighted magnetic resonance imaging, the fat and tissue volumes in the necks of 10 non-obese men and 10 women matched for age (men mean (SE) 36 (3) years, women 37 (3) years, $p=0.7$ ), body mass index (both 25 (0.6) $\mathrm{kg} / \mathrm{m}^{2}, \mathrm{p}>0.9$ ), and Epworth Sleepiness Score (both $5(1), p=0.9$ ) were assessed; all denied symptoms of SAHS.
\end{abstract}

Results-Total neck soft tissue volume was greater in men (1295 (62) vs $928(45) \mathrm{cm}^{3}$, $p<0.001$ ), but the volume of fat did not differ between the sexes (291 (29) vs 273 (18) $\left.\mathrm{cm}^{3}, p=0.6\right)$. The only regions impinging on the pharynx which showed a larger absolute volume of fat in men (3.2 $(0.7)$ vs $\left.1.1(0.3) \mathrm{cm}^{3}, \mathrm{p}=0.01\right)$ and also a greater proportion of neck fat in men (1.3 $(0.3) \%$ vs $0.4(0.1) \%, p=0.03)$ were the anterior segments inside the mandible at the palatal level.

Conclusions-There are differences in neck fat deposition between the sexes which, together with the greater overall soft tissue loading on the airway in men, may be factors in the sex distribution of SAHS.

(Thorax 1999;54:323-328)

Keywords: sleep apnoea; neck fat; sex differences; magnetic resonance imaging

Western General Hospital, Edinburgh EH4 2XU, UK

Correspondence to: Dr A T Whittle.

Received 25 June 1998 Returned to authors 17 August 1998 Revised version received 18 September 1998 Accepted for publication 17 November 1998 sleep apnoea/hypopnoea syndrome (SAH women in all adult age groups. ${ }^{12}$ In men these conditions are associated with obesity, increased neck circumference, and reduced cross sectional area of the upper airway, ${ }^{3-6}$ all factors which predispose to the partial or complete obstruction of the upper airway.
The male predominance in SAHS has not been fully explained and is in some respects paradoxical. Compared with men, a greater proportion of total body soft tissue in normal women is fat and obesity is more frequent in women. ${ }^{78} \mathrm{~A}$ condition strongly associated with obesity might therefore be predicted to show a higher frequency in women. Similarly, pharyngeal airway cross sectional area has been reported to be less in women when matched for body mass index (BMI), ${ }^{9}$ which would be expected to predispose to airway obstruction. However, women do have a smaller neck circumference when matched for BMI and so overall mass loading on the upper airway may be less. ${ }^{10}$ Dynamic factors are also relevant; the upper airway when seated is smaller in women, but there is no difference between supine men and women. ${ }^{10}$ This suggests that women have a greater ability to defend the airway against posture related changes, and a higher waking upper airway dilating muscle tone in women may provide a physiological basis for this. ${ }^{11}$

Magnetic resonance imaging (MRI) has become an established method for the in vivo quantification of fat tissue. ${ }^{12} 13$ Fat has a relatively short $\mathrm{T} 1$ relaxation time, so fatty tissue has a higher intensity than other soft tissues in T1 weighted spin echo MRI images. The availability of this technique has prompted a number of studies which have attempted to clarify the relationship between obesity and upper airway obstruction at a detailed anatomical level. Although there is a clear relationship between overall neck size and airway obstruction in men, ${ }^{3}$ there is still controversy about the significance of the precise anatomical distribution of fat deposition in the neck. Horner et al observed fat pads lateral to the airway which were larger in obese SAHS patients than in weight matched controls, ${ }^{14}$ and our group made similar findings in non-obese patients compared with matched controls. ${ }^{15}$ Shelton et al found that the volume of fat in this region correlated with the frequency of apnoeas/ hypopnoeas in a mixed group of patients and normal subjects. ${ }^{4}$ Schwab et al questioned the significance of the fat pads, reporting that although their volume was increased in SAHS patients compared with unmatched less obese normal subjects, the patients did not show a greater area of fat pad than normal subjects at the level of the minimum airway area. ${ }^{5}$

We have tested the hypothesis that fat deposition adjacent to the upper airway may be greater in men than in women, and so may be 
A

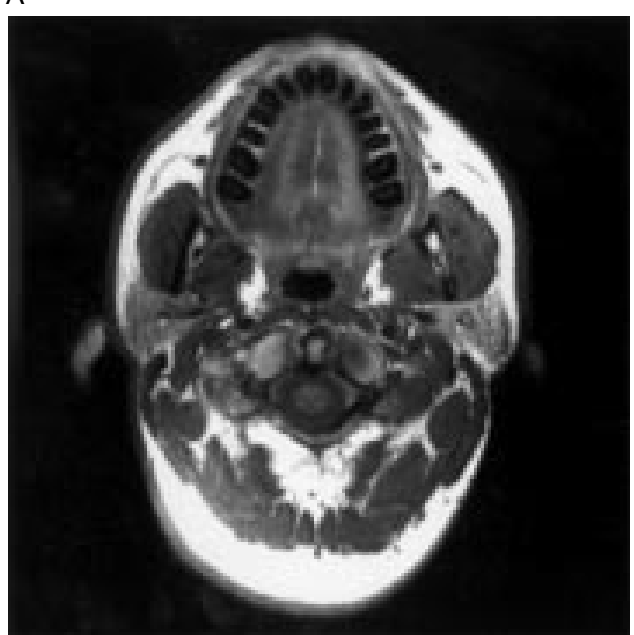

B

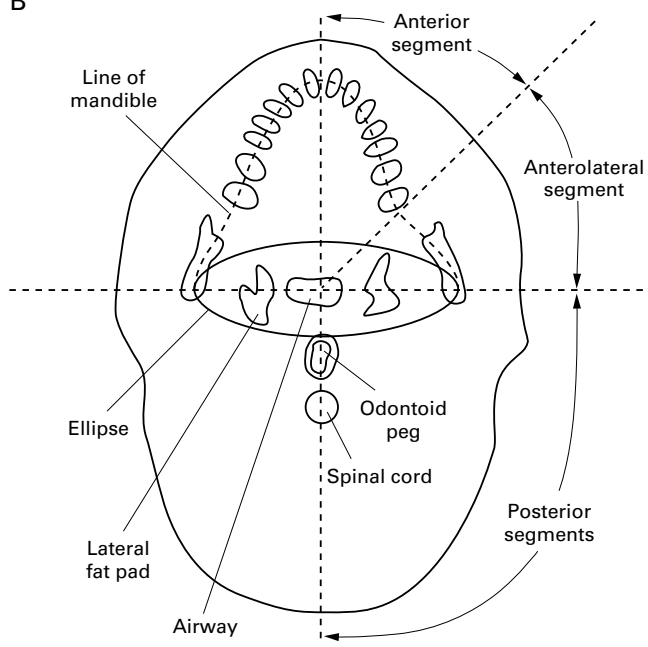

Figure 1 (A) Representative transverse T1 weighted magnetic resonance image of the neck of a normal man. (B) Diagrammatic representation of the image in A illustrating the segmental divisions used for analysis of neck fat volumes, the subdivision of the anterior and anterolateral segments by the line of the mandible, and the position of the ellipse used for analysis of fat volumes close to the airway.

one factor underlying the sex distribution of conditions related to upper airway obstruction. We studied with MRI the deposition of fat in the necks of normal adult men and women, closely matched for age and degree of obesity as measured by body mass index.

\section{Methods}

SUBJECTS

Ten male and 10 female volunteers, matched for age and body mass index, gave informed consent to the study. All denied snoring, daytime sleepiness, and other symptoms of SAHS, ${ }^{2}$ and had Epworth Sleepiness Scores of 12 or less. ${ }^{16}$ We did not perform sleep studies on these normal subjects but, by definition, they did not have SAHS as they denied all major symptoms. ${ }^{2}$ Weight, height, neck circumference at the level of the superior border of the cricothyroid membrane, ${ }^{3}$ and skin fold thickness were determined by a medical practitioner (ILM or ATW) at the time of MRI scanning. Body fat content was calculated by the method of Durnin and Rahaman from skin fold thickness measured with callipers over the biceps and triceps and at subscapular and suprailiac sites. ${ }^{17}$

IMAGING AND ANALYSIS

The equipment and protocol for acquisition of transverse and sagittal T1 weighted magnetic resonance images of the neck in the region of the upper airway have been described in our previous work. ${ }^{15}$ Image data were transferred to an independent workstation (Sun Microsystems Inc, Mountain View, California, USA) and analysed using the ANALYZE package (Mayo Foundation, Rochester, New York, USA).

To calculate fat and tissue volumes each transverse spin echo image was analysed for total and fatty tissue areas. Tissue areas were analysed in eight radial segments centred on the airway, each subtending $45^{\circ}$. The radial dividers were rotated in order to align the anterior-posterior axis with anatomical fea- tures. The anterior and anterolateral segments were subdivided by the line of the mandible (fig 1). As in our previous work, ${ }^{15}$ total soft tissue and fat areas were determined using thresholds chosen from inspection of each image. For some subjects these thresholds were altered from segment to segment within the image and from slice to slice to allow for inhomogeneities in the gray scale within and between slices-for example, in areas below the epiglottis where coil sensitivity was reduced. Volumes were derived from the sum of areas in each segment and the known distance between each slice. The reproducibility of the determination of fat and tissue volumes from scans of men by this method has been reported previously. ${ }^{15}$ Volumes were calculated for the entire neck related to the upper airway, from the level of the top of the palate to the top of the larynx. This was subdivided into the palatal section of the neck, from the top of the palate to the tip of the uvula, and the subpalatal section, from the tip of the uvula to the top of the larynx.

Fat close to the airway was analysed by construction of an ellipse centred on the airway, limited by the spinal column posteriorly and by the intersection of the line of the mandible with the projected airway midline laterally (fig 1). This form of ellipse was chosen to include the fat pads which lie lateral to the airway. ${ }^{14}$ Fat areas were again determined using thresholds derived from inspection of the image being analysed, and volumes were derived as before.

Airway cross sectional area was determined on the transverse spin echo images. The method was semi-automatic, "growing" a region of interest (ROI) from a "seed" placed in the centre of the airway, adjusting the threshold to include the airspace but not the airway walls. The scan times included several respiratory cycles, so the airway dimensions were effectively averaged over the cycle. This adds "noise" to the data and will tend to reduce the significance of observed differences. The airway area on each image slice was noted, with the slice showing the smallest area taken to 
Table 1 Mean (SE) characteristics of study subjects

\begin{tabular}{lll}
\hline & Men & Women \\
\hline Age (years) & $36(3)$ & $37(3)$ \\
Epworth sleepiness score & $5(0.9)$ & $5(1.0)$ \\
Body mass index $\left(\mathrm{kg} / \mathrm{m}^{2}\right)$ & $25(0.6)$ & $25(0.6)$ \\
Weight $(\mathrm{kg})$ & $81(3)$ & $67(2)^{\star}$ \\
Body fat $(\%)$ & $17(1.4)$ & $33(1.2)^{\star \star}$ \\
Body fat mass $(\mathrm{kg})$ & $14(1.3)$ & $22(1.1)^{\star \star}$ \\
Body fat-free mass $(\mathrm{kg})$ & $68(3)$ & $45(2)^{\star \star}$ \\
Neck circumference $(\mathrm{cm})$ & $38(0.5)$ & $33(0.4)^{\star \star}$ \\
\hline$\star_{\mathrm{p}<0.01 ;{ }^{\star \star} \mathrm{p}<0.001 .}$ &
\end{tabular}

represent the site and size of the anatomical minimum airway area. Average cross sectional area was the sum of the areas observed on the slices covering the relevant region divided by the number of slices. An ROI was also drawn around the tongue and around the soft palate on the sagittal image showing the airway midline, and their total areas were determined. The area of fatty tissue within the ROI was determined by counting pixels with an intensity above a certain threshold: the threshold was selected subjectively by reference to known fatty anatomical features on the same image such as subcutaneous fat.

\section{STATISTICAL ANALYSIS}

Data were analysed and statistical calculations performed using Microsoft Excel 5.0 (Microsoft Corporation, Redmond, WA). All anatomical variables were normally distributed and are quoted as means with standard errors of the mean; mean values in men and women were compared with the unpaired two-tailed Student's $t$ test, defining significance as $\mathrm{p}<0.05$. Category comparisons were performed with the $\chi^{2}$ test.

\section{Results}

SUBJECT CHARACTERISTICS

The men and women were matched for age, body mass index, and subjective sleepiness as assessed by the Epworth Sleepiness Scale. The men showed higher mean body weight, fat free mass and neck circumference, while percent-

Table 2 Mean (SE) soft tissue (including fat) and fat volumes analysed in segments at the palatal and subpalatal levels. Fat volumes are also expressed as percentages of the soft tissue in each defined region and as a percentage of the total neck fat volume

\begin{tabular}{|c|c|c|c|c|}
\hline & \multicolumn{2}{|c|}{ Palatal level } & \multicolumn{2}{|c|}{ Subpalatal level } \\
\hline & Men & Women & Men & Women \\
\hline \multicolumn{5}{|c|}{ Anterior segments inside mandible: } \\
\hline Soft tissue $\left(\mathrm{cm}^{3}\right)$ & $62(3)$ & $41(3)^{\star \star \star}$ & $99(8)$ & $85(4)$ \\
\hline Fat $\left(\mathrm{cm}^{3}\right)$ & $3.2(0.7)$ & $1.1(0.3)^{\star}$ & $21(3)$ & $27(2)$ \\
\hline Fat as $\%$ of soft tissue & $5(1.0)$ & $3(1.0)$ & $21(2)$ & $32(3)^{\star \star}$ \\
\hline Fat as $\%$ of total neck fat & $1.3(0.3)$ & $0.4(0.1)^{\star}$ & $7(0.7)$ & $10(1.0)^{\star}$ \\
\hline \multicolumn{5}{|c|}{ Anterolateral segments inside mandible: } \\
\hline Soft tissue $\left(\mathrm{cm}^{3}\right)$ & $25(2.4)$ & $15(1.5)^{\star \star}$ & $64(5)$ & $49(3)^{\star}$ \\
\hline Fat $\left(\mathrm{cm}^{3}\right)$ & $1.5(0.2)$ & $1.2(0.2)$ & $16(3)$ & $18(2)$ \\
\hline Fat as $\%$ of soft tissue & $7(1.2)$ & $9(1.3)$ & $23(3)$ & $37(2)^{\star \star}$ \\
\hline Fat as $\%$ of total neck fat & $0.6(0.09)$ & $0.4(0.05)$ & $5(0.5)$ & $7(0.4)^{\star}$ \\
\hline \multicolumn{5}{|c|}{ Anterior and anterolateral segments outside mandible: } \\
\hline Soft tissue $\left(\mathrm{cm}^{3}\right)$ & $138(9)$ & $89(4)^{\star \star \star}$ & $72(6)$ & $62(5)$ \\
\hline Fat $\left(\mathrm{cm}^{3}\right)$ & $37(3.6)$ & $30(1.5)$ & $18(3)$ & $29(3)^{\star}$ \\
\hline Fat as $\%$ of soft tissue & $27(1.3)$ & $33(0.9)^{\star \star}$ & $29(3)$ & $47(2)^{\star \star \star}$ \\
\hline Fat as $\%$ of total neck fat & $14(1.6)$ & $11(0.9)$ & $7(0.7)$ & $11(1.1)^{\star \star}$ \\
\hline \multicolumn{5}{|l|}{ Posterior segments: } \\
\hline Soft tissue $\left(\mathrm{cm}^{3}\right)$ & $333(16)$ & $199(16)^{\star \star \star}$ & $509(45)$ & $388(25)^{\star}$ \\
\hline Fat $\left(\mathrm{cm}^{3}\right)$ & $84(8)$ & $59(6)^{\star}$ & $111(16)$ & $108(10)$ \\
\hline Fat as $\%$ of soft tissue & $25(3)$ & $30(2)$ & $20(2.5)$ & $28(1.7)^{\star}$ \\
\hline Fat as $\%$ of total neck fat & $30(2.9)$ & $21(1.3)^{\star \star}$ & $36(4)$ & $39(2)$ \\
\hline
\end{tabular}

Significance of differences between men and women in each region: ${ }^{\star} \mathrm{p}<0.05 ;{ }^{\star \star} \mathrm{p}<0.01$; $\star \star \star \mathrm{p}<0.001$ age body fat content and total body fat mass were higher in women (table 1). The necks of men required more equidistant image slices to cover the full length of the neck (mean (SE) 18 (0.8) slices, $7(0.4)$ above the uvula and 12 (0.8) below) than those of women (16 (0.4) slices in total $(\mathrm{p}=0.02), 5(0.3)$ above the uvula $(\mathrm{p}=0.002)$ and $11(0.2)$ below ( $\mathrm{p}=$ $0.6)$ ), reflecting the greater length of the necks of men.

NECK FAT AND TISSUE VOLUMES

The total neck soft tissue volume was larger in men $\left(1295(62) \mathrm{cm}^{3}\right)$ than in women (928 (45) $\left.\mathrm{cm}^{3}, \mathrm{p}=0.0002\right)$. This difference was made up by non-fat soft tissue; the actual volume of fat was similar in the two sexes (291 (29) vs $\left.273(18) \mathrm{cm}^{3}, \mathrm{p}=0.6\right)$. The pattern was not altered when allowance was made for the greater length of men's necks by correcting for the number of image slices from which the volume was derived (soft tissue, 71 (3) $\mathrm{cm}^{3} /$ slice for men vs 57 (2) $\mathrm{cm}^{3} /$ slice for women, $\mathrm{p}=$ 0.001 ; fat volume, $16(2) \mathrm{cm}^{3} /$ slice for men vs 17 (1) $\mathrm{cm}^{3} /$ slice for women, $\left.\mathrm{p}=0.5\right)$. Fat volume as a percentage of total soft tissue volume was therefore significantly higher in the necks of women $(22$ (2)\% vs 29 (1) \%, p = $0.002)$. If within each sex the percentage of fat in the neck soft tissue (derived from the MRI scans) was compared with the percentage of fat in the whole body (derived from skin fold measurements), then in men there was a greater proportion of fat in the neck than in the body as a whole (neck fat 22 (2)\% of neck tissue vs whole body fat 17 (11)\% of body mass, $\mathrm{p}<0.05$ ). In women the reverse was true (neck fat 29 (1) \% vs body fat $33(1) \%, p<0.05)$.

REGIONAL DISTRIBUTION OF NECK FAT

Fat distribution was analysed with the neck divided longitudinally into palatal and subpalatal sections, and radially into segments centred on the airway (fig 1). This analysis identified two regions in which men had a larger absolute volume of fat than women (table 2 , fig $2 \mathrm{~A}$ ). In the anterior segments inside the mandible at the palatal level, which are adjacent to the airway, overall fat volumes were small but were significantly greater in men than in women $(p=$ 0.01 ). There was also significantly more fat in the posterior segments at the palatal level in men ( $p=0.03)$; inspection of the images suggested that this was largely due to subcutaneous fat at the back of the neck. The remainder of the segmental analysis showed a pattern of significantly greater non-fat soft tissue volumes in men than in women, but similar volumes of fat in the two sexes. When fat volumes were considered as percentages of the volume of soft tissue in each region, there was a consistently higher percentage of fat in women which did not always reach statistical significance (table 2). The exceptions were the anterior segments inside the mandible at the palatal level.

To analyse the pattern of fat distribution without any bias from the sex difference in absolute tissue volumes, the fat volume in each region was also considered as a percentage of the total neck fat volume for that individual 
(table 2; fig 2B). Again, there was greater deposition of fat in men in the anterior segments inside the mandible at the palatal level $(p=0.03)$ and in the posterior segments at the palatal level $(\mathrm{p}=0.01)$. Overall, 46 (4.4)\% of total neck fat in men was at the palatal level compared with $33(1.8) \%$ in women ( $p$ $=0.01)$. The bulk of this fat was in the posterior segments or in the parts of the anterior and anterolateral segments outside the line of the mandible (fig 2).

TONGUE, SOFT PALATE AND LATERAL FAT PADS The mean cross sectional area of the tongue on the midline sagittal image was greater in men than in women $\left(31(1.5) \mathrm{cm}^{2}\right.$ vs $26(0.8) \mathrm{cm}^{2}$, p $=0.02)$. Neither the absolute area of the tongue comprised of pixels of fat intensity (2.3 $(0.7) \mathrm{cm}^{2}$ vs $\left.2.1(0.3) \mathrm{cm}^{2}, \mathrm{p}=0.8\right)$ nor the proportional area of fat $(8(3.0) \%$ vs $8(1.2) \%$, $\mathrm{p}=0.9$ ) differed between men and women. Similarly, the mean cross sectional area of the soft palate on the same image was greater in men than in women (459 (34) $\mathrm{mm}^{2}$ vs 318 (27) $\left.\mathrm{mm}^{2}, \mathrm{p}=0.005\right)$, while the area of fat and the percentage of fat did not differ between the
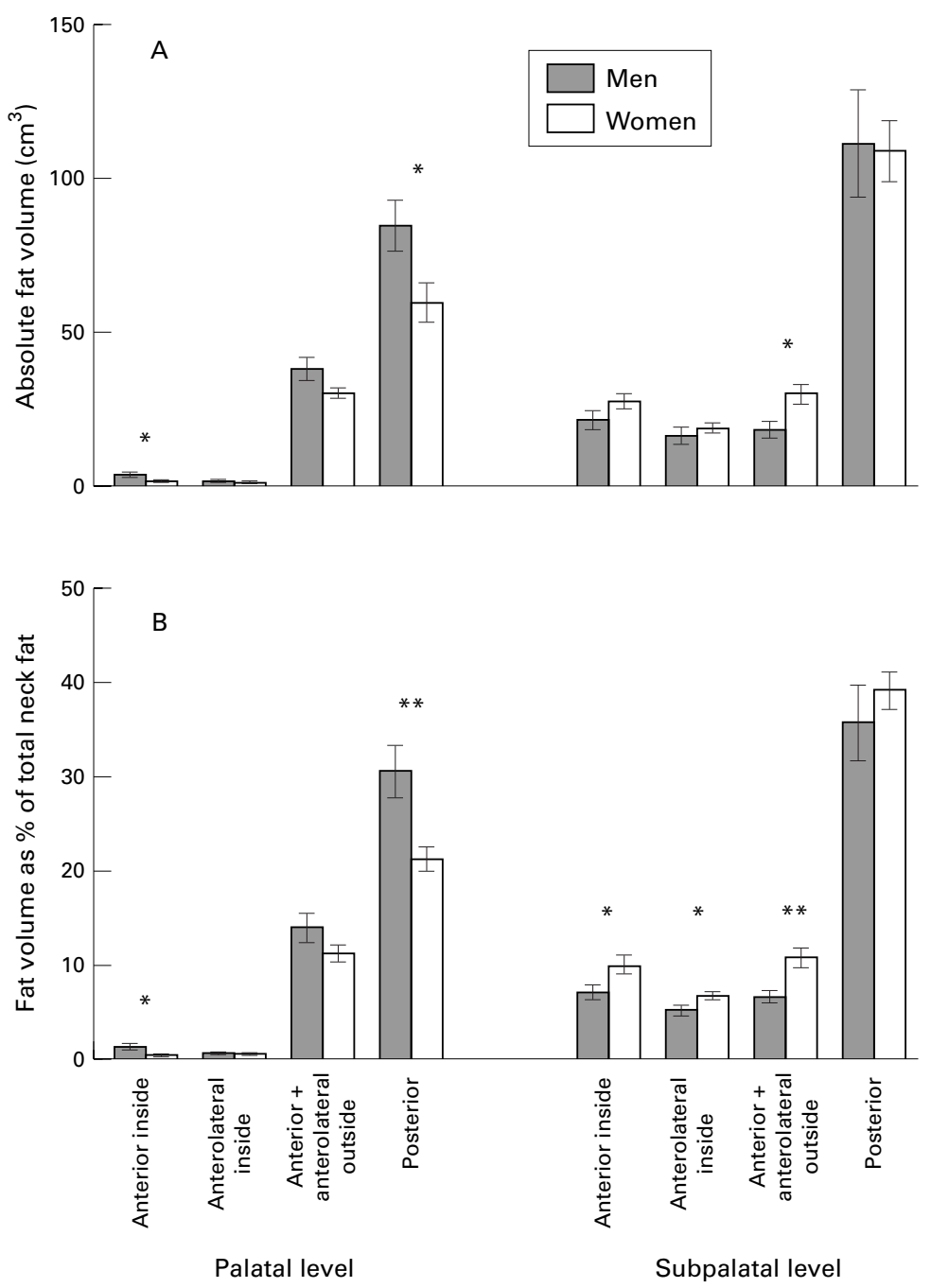

Figure 2 Mean (SE) distribution of neck fat in men and women: (A) absolute volumes; (B) proportional distribution of fat volume in each region as a percentage of total neck fat for that individual. Significance of difference between men and women: ${ }^{\star} p<0.05$; $\star * p<0.01$.
Table 3 Mean (SE) pharyngeal airway dimensions $\left(\mathrm{mm}^{2}\right)$

\begin{tabular}{|c|c|c|}
\hline & Men & Women \\
\hline \multicolumn{3}{|c|}{ Average airway cross sectional area: } \\
\hline Whole neck & $130(9)$ & $109(12)$ \\
\hline Palatal region & $78(9)$ & $85(12)$ \\
\hline Subpalatal region & $160(12)$ & $119(13)^{\star}$ \\
\hline \multicolumn{3}{|c|}{ Minimum cross sectional area: } \\
\hline Whole neck & $41(5)$ & $37(7)$ \\
\hline Palatal region & $45(5)$ & $52(12)$ \\
\hline Subpalatal region & $67(9)$ & $49(5)$ \\
\hline
\end{tabular}

${ }^{{ }_{\mathrm{p}}<0.05}$.

sexes (51 (15) $\mathrm{mm}^{2}$ vs $46(11) \mathrm{mm}^{2}, \mathrm{p}=0.8 ; 14$ (5) $\%$ vs $14(3) \%, p=0.9)$.

The ellipses constructed to contain the fat pads lateral to the airway, extended through all the image slices on which these pads were visible, contained a mean total volume of 41 (2.2) $\mathrm{cm}^{3}$ in men and $39(1.9) \mathrm{cm}^{3}$ in women $(p=0.5)$. Within this, the volume of fat was 2.7 $(0.4) \mathrm{cm}^{3}$ in men and $3.2(0.4) \mathrm{cm}^{3}$ in women $(\mathrm{p}=0.4)$.

AIRWAY

The minimum cross sectional area of the airway did not differ significantly between the sexes (table 3). The minimum area was observed on a slice in the palatal region in seven of 10 men and in five of 10 women ( $p=$ 0.4 ). Mean airway cross sectional area was similar in men and women when considered over the whole length of the neck and also in the palatal region. In the subpalatal region the mean airway area was significantly greater in men (table 3).

\section{Discussion}

This study has shown that the pattern of fat deposition in the neck close to the upper airway differs between men and women and that the larger soft tissue volume in the necks of men is mainly due to soft tissue other than fat. It has also shown that the necks of men contain a higher proportion of fat than their bodies as a whole, while the reverse is true of women matched for BMI.

We found only one region closely related to the airway in which men showed a significantly greater absolute volume of fat than womennamely, the anterior segments inside the line of the mandible at the palatal level. Men also had a greater proportionate deposition of neck fat in these segments than women, so this observation is not due to the greater length or diameter of the male neck. These segments may be of pathophysiological significance in snoring and sleep disordered breathing as they will contribute to mass loading on the palatal airway, a frequent site of sleep related airway obstruction in SAHS. ${ }^{18}{ }^{19}$ As these segments are anterior to the airway, loading will be greatest when the subject lies supine, the position in which sleep disordered breathing is most severe. ${ }^{2021}$

The major anatomical structures in the anterior segments inside the mandible at the palatal level, which showed greater fat deposition in men, are the soft palate and the upper part of the tongue. We analysed the cross sectional areas of tissue and fat in these 
structures in the medial sagittal plane and found no sex difference in fat deposition. This could be explained by non-uniform fat deposition within the tongue; in particular, the midline fibrous septum of the tongue (which is imaged on the midline sagittal section) showed few pixels of fat density on our images, as the small fat deposits in the tongue were scattered through the muscle bundles. The segmental volume analysis may therefore demonstrate a genuine difference which is not detectable on cross section area analysis.

These findings concerning differences between the sexes in fat deposition must be interpreted with caution. Although the anterior segments inside the mandible at the palatal level are potentially important in the pathophysiology of sleep disordered breathing, the absolute volume of fat in this region is small; indeed, these segments showed the least fat as a proportion of soft tissue of all the regions analysed (table 2, fig 2). Upper airway collapse during sleep can also occur in the retroglossal airway below the level of the uvula ${ }^{18} 19$ and the anterior and anterolateral segments in this region showed greater proportionate fat deposition in women. The effect of sex on the site of airway collapse in SAHS has not been studied and, in particular, it is not known whether the retroglossal airway is more prone to collapse during sleep in women than in men; this study has shown that women have both greater fat deposition and a narrower airway in this area.

The greatest differences in fat deposition between the sexes, and the largest volumes of neck fat in both sexes, were found in the segments posterior to the airway. Fat here is largely posterior to the spinal column and is unlikely to provide significant mass loading on the airway during sleep (fig 1). The regions outside the mandible in the anterior part of the neck are also less directly relevant to the airway, although increased tissue bulk could predispose to jaw opening during sleep and hence contribute to upper airway narrowing. Men showed greater soft tissue volume here, as in most other regions, but fat deposition was not significantly different between the sexes at the palatal level and was greater in women at the subpalatal level (fig 2).

Discussion of the significance of the differences in fat distribution should not obscure the major difference between the sexes observed in this study. The overall volume of soft tissue was greater in the male neck, both as a whole and in every segment analysed (table 2), and men had more bulky tongues and soft palates. Non-fat soft tissue made up the greatest part of this difference since the fat volume was similar in men and women. This tissue is predominantly muscle, and reduction in muscle tone during sleep will increase the significance of simple tissue bulk as a factor in airway collapse.

The airway dimensions we have observed are compatible with our previously published findings of similar average cross sectional airway dimensions in supine men and women when considering the whole length of the airway. ${ }^{10}$ The technique of MRI allows us to analyse the airway at different levels, and in this study we have found significantly greater mean cross sectional area in the subpalatal airway in men. Minimum cross sectional airway area may be more important than mean values when considering the propensity of the airway to collapse, and we found no difference between the sexes in minimum area, and also no difference in the anatomical site of the minimum area.

Potential problems inherent in this study include the matching of the populations and the limitations of the measurement and statistical techniques used. There is no ideal method to match men and women for the degree of obesity, given that both body fat content and overall body size differ between the sexes and that no single "body mass index" provides an ideal non-biased measure of obesity in both men and women. ${ }^{22}$ We have chosen the formula for body mass index originally devised by Quetelet (weight $/$ height $^{2}$ ) as it is a well characterised and widely used anthropometric index of obesity. ${ }^{23}{ }^{24}$ It provides similar (although not identical) average values in men and women, and is suitable for anthropometric purposes as it is independent of the concept of "ideal weights" calculated from mortality data which differ between the sexes. ${ }^{22}$ Men and women matched by BMI will inevitably show different ranges of neck circumference and body fat content. ${ }^{1025}$ If the sexes were matched for either neck circumference or body fat, the comparisons would then be made between two populations unrepresentative of "normality" for their respective sexes; indeed, these populations would represent opposite extremes of obesity in each sex.

Potential limitations of the measurement technique include the need to use nonautomatic thresholding of the images to separate fat from other tissues on each image. This was because of within-slice and betweenslice variations in intensity due to nonuniformities in sensitivity of MRI neck coils when a subject is in place-as seen, for example, in the intensity of the two parotid glands in fig 1A. This problem was compounded by the similar intensity to fat on $\mathrm{T} 1$ weighted images of some other neck tissues, particularly parotid. In order to give satisfactory separation of tissue types during image analysis it was therefore necessary to introduce some subjectivity into the measurements by varying the fat threshold, judged from anatomical features, between different segments as each image was analysed. In our images, fat typically has an intensity 2-3 times that of other soft tissues. It is possible that, despite this, small volumes of tissues such as lymphatics have been included as "fat" in our analysis. In future studies these problems may be reduced by improved $\mathrm{T} 1$ weighted pulse sequences with less susceptibility to coil inhomogeneity. Subjectivity in image interpretation also proved unavoidable in the determination of tongue area on the midline sagittal image; the lower border of the tongue was not clearly defined by variations in image intensity and had to be defined by reference to known anatomical structures. We have previously reported the repeatability of our method for 
assessment of fat volumes ${ }^{15}$ which has a coefficient of variation of $11 \%$. This variability would tend to obscure rather than exaggerate the significance of the observed differences. A further reason for caution in the interpretation of our results is the problem inherent in all studies involving more than one statistical comparison. This paper contains comparisons of 66 pairs of data, thus three comparisons would be expected to show significant differences $(p<0.05)$ through chance alone.

In conclusion, the sex difference in the prevalence of sleep disordered breathing is likely to be multifactorial. We have found significant differences between normal men and women in the pattern of deposition of fat close to the upper airway which may be one factor. The larger overall soft tissue bulk of the male neck in combination with dynamic effects of differing muscle activity may, however, prove to be of greater significance.

The authors thank the staff of the Edinburgh Sleep Centre and the radiographers of the MRI Unit, Western General Hospital. the radiographers of the MRI Unit, Western General Hospital. Trust.

1 Young T, Palta M, Dempsey J, et al. The occurrence of sleep Young T, Palta $M$, Dempsey J, et al. The occurrence of sleep Med 1993;328:1230-5.

2 Whyte KF, Allen MB, Jeffrey AA, et al. Clinical features of the sleep apnoea/hypopnoea syndrome. $Q \mathcal{F} \mathrm{Med} 1989 ; 72$ : 659-66.

3 Katz I, Stradling J, Slutsky AS, et al. Do patients with obstructive sleep apnea have thick necks? Am Rev Respir Dis 1990;141:1228-31.

4 Shelton KE, Woodson H, Gay S, et al. Pharyngeal fat in obstructive sleep apnea. Am Rev Respir Dis 1993;148:4626.

5 Schwab RJ, Gupta KB, Gefter WB, et al. Upper airway and soft tissue anatomy in normal subjects and patients with sleep disordered breathing. Am $\mathcal{F}$ Respir Crit Care Med 1995;152:1673-89.

6 Bradley TD, Brown IG, Grossman RF, et al. Pharyngeal size in snorers, non-snorers, and patients with obstructive sleep in snorers, non-snorers, and patients with
apnea. N Engl f Med 1989;315:1327-31.
7 Durnin JGVA, Womersley J. Body fat assessed from total body density and its estimation from skinfold thickness: measurements on 481 men and wor

8 Kuczmarski RJ, Flegal KM, Campbell SM, et al. Increasing prevalence of overweight among US adults. The National Health and Nutrition Examination Surveys, 1960 to 1991. FAMA 1994;272:205-11.

9 Brooks LJ, Strohl KP. Size and mechanical properties of the pharynx in healthy men and women. Am Rev Respir Dis 1992;148:1394-7.

10 Martin SE, Mathur R, Marshall I, et al. The effect of age, sex, obesity and posture on upper airway size. Eur Respir $\mathcal{F}$ 1997;10:2087-90.

11 Popovic RM, White DP. Influence of gender on waking genioglossal electromyogram and upper airway resistance. $\mathrm{Am}$ F Respir Crit Care Med 1995;152:725-31.

12 Staten MA, Totty WG, Kohrt WM. Measurement of fat distribution by magnetic resonance imaging. Invest Radiol 1989;24:345-9.

13 Ross R, Leger L, Morris D, et al. Quantification of adipose tissue by MRI: relationship with anthropometric variables. 7 Appl Physiol 1992;72:787-95.

14 Horner RL, Mohiaddin RH, Lowell DG, et al. Sites and sizes of fat deposits around the pharynx in obese patients with obstructive sleep apnoea and weight matched with obstructive sleep apnoea and
controls. Eur Respir f 1989;2:613-22.

15 Mortimore IL, Marshall I, Wraith PK, et al. Neck and total body fat deposition in nonobese and obese patients with sleep apnea compared to control subjects. Am $\mathcal{F}$ Respir Crit Care Med 1998;157:280-3.

16 Johns MW. A new method for measuring daytime sleepiness: the Epworth Sleepiness Scale. Sleep 1991;14: $540-5$.

17 Durnin JVGA, Rahaman MM. The assessment of the amount of fat in the human body from measurements of skinfold thickness. Br F Nutr 1967;21:681-9.

18 Hudgel DW. Variable site of airway narrowing among obstructive sleep apnea patients. F Appl Physiol 1986;61: 1403-9.

19 Shepard JW Jr, Thawley SE. Localisation of upper airway collapse during sleep in patients with obstructive sleep apnea. Am Rev Respir Dis 1990;141:1350-5.

20 apnea. Am Rev Respir Dis 1990;141:1350-5.

21 McEvoy RD, Sharp DJ, Thornton AT. The effects of posture on obstructive sleep apnea. Am Rev Respir Dis 1986;133:662-6.

22 Stavig GR, Leonard AR, Igra A, et al. Indices of relative body weight and ideal weight charts. $\mathcal{F}$ Chron Dis 1984;37: 255-62.

23 Quetelet LAJ. Physique social. Brussels: C Muquardt, 1869: Vol 2, 92

24 Keys A, Fidanza F, Karvonen MJ, et al. Indices of relative weight and obesity. F Chron Dis 1972;25:329-43.

25 Gallagher D, Visser M, Sepulveda D, et al. How useful is body mass index for comparison of body fatness across age, sex and ethnic groups? Am f Epidemiol 1996;143:228-39. 